\title{
Trauma Surgery \& Acute Care Open \\ Variation in the use of MRI for cervical spine clearance: an opportunity to simultaneously improve clinical care and decrease cost
}

\author{
Alia Albaghdadi, ${ }^{1}$ Ira L. Leeds, ${ }^{1}$ Katherine L. Florecki, ${ }^{2}$ Joseph K. Canner, ${ }^{1}$ \\ Eric B. Schneider, ${ }^{1}$ Joseph V. Sakran, ${ }^{1}$ Elliott R. Haut ${ }^{\oplus}$
}

'Department of Surgery, Johns Hopkins University School of Medicine, Baltimore, Maryland, USA

${ }^{2}$ Department of Surgery, Sinai Hospital, Baltimore, Maryland, USA

Correspondence to Dr Elliott R. Haut, Johns Hopkins Medicine, Baltimore, MD 21218, USA; ehaut1@jhmi.edu

This work was originally presented at the 2016 Academic Surgical Congress in Jacksonville, Florida, USA.

Received 26 May 2019 Accepted 7 June 2019 (c) Author(s) (or their employer(s)) 2019. Re-use permitted under CC BY-NC. No commercial re-use. See rights and permissions. Published by BMJ.

To cite: Albaghdadi A, Leeds IL, Florecki KL, et al. Trauma Surg Acute Care Open 2019:4:e000336.

\section{ABSTRACT}

Background For years, controversy has existed about the ideal approach for cervical spine clearance in obtunded, blunt trauma patients. However, recent national guidelines suggest that MRI is not necessary for collar clearance in these patients. The purpose of this study was to identify the extent of national variation in the use of MRI and assess patient-specific and hospitalspecific factors associated with the practice.

Methods We performed a retrospective review of the National Trauma Data Bank from 2007 to 2012. We included blunt trauma patients aged $\geq 18$ years, admitted to level 1 or 2 trauma centers (TCS), with a Glasgow Coma Scale $<8$, Abbreviated Injury Scale $>3$ for the head and mechanically ventilated for more than 72 hours. Multilevel modeling was used to identify patient-level and hospital-level factors associated with spine MRI use. Results 32125 obtunded, blunt trauma patients treated at 395 unique TCs met our inclusion criteria. The mean proportion of patients who received MRI over the entire sample was $9.9 \%$. The proportions of patients at each hospital who received a spine MRI ranged from $0.5 \%$ to $68.7 \%$. Younger patients, with injuries from motor vehicle collisions and pedestrian injuries, were more likely to receive MRI. When controlling for other variables, Injury Severity Score (ISS) was not associated with MRI use. Hospitals in the Northeast, level 1 TCs and non-teaching hospitals were more likely to obtain MRIs in this patient population.

Conclusion After controlling for patient-level characteristics, variation remained in MRI use based on geography, trauma center level and teaching status. This evidence suggests that current national guidelines limiting the use of MRI for cervical spine evaluation following blunt trauma are not being followed consistently. This may be due to physicians not being up to date with best practice care, unavailability of locally adopted protocols in institutions or lack of consensus among clinical providers.

Level of evidence Prognostic and epidemiological, level III.

\section{INTRODUCTION}

Improper early clearance and missed unstable cervical spine injuries result in life-long disability and lifetime costs of over US $\$ 2$ million. ${ }^{1}$ Not only can these injuries be missed due to more acute physiological insults at the time of presentation, such as hemorrhage and airway compromise, but cervical spine injuries can also manifest in a delayed fashion where spine instability leads to a secondary injury days later. To further complicate the diagnosis and management of these injuries, early identification of cervical spine injuries is dependent on patient's cooperation. The estimated prevalence of cervical spine injury in alert trauma patients is $2.7 \%$, but the risk is $7.7 \%$ in obtunded patients. ${ }^{2}$

Trauma patients frequently present with depressed mental status, and the increased risk of cervical spine injury in this subgroup leads to prolonged collar immobilization. Prolonged collar immobilization exposes patients to multiple in-hospital risks. The risk of collar-related pressure ulcers increases by $66 \%$ for every additional day of use. ${ }^{3}$ Additional complications of delayed collar clearance include: difficult intubation, difficult central line insertion, increased intracranial pressure (ICP) and secondary brain injury due to internal jugular compression and additional positioning and aspiration pneumonia with subsequent delayed weaning from ventilators. ${ }^{4-7}$ Historically, a commonly suggested adjunct study for collar clearance in obtunded, blunt trauma patients has been MRI. ${ }^{4} 9$ Delays in collar clearance have been attributed to systems-related issue and resource scarcity issue owing to the need for MRI. Many authors have also suggested minimizing the need for collar placement initially, in particular for patients with penetrating trauma. ${ }^{9-11}$ Finally, manual in-line stabilization of the cervical spine in adults has been shown to increase the tracheal intubation failure rate and reduce visualization during direct laryngoscopy. ${ }^{12}$

The combination of risk exposure with prolonged immobilization as well as catastrophic consequences of missed cervical spine injuries has led to increased attention for early, safe removal of cervical collars. Multiple iterations of national trauma guidelines, Eastern Association for the Surgery of Trauma (EAST) and Western Trauma Association (WTA), have evolved to suggest that the absence of findings on a high-quality CT scan of the cervical spine is adequate for collar clearance-largely due to technological advancements in this modality and extreme low-likelihood of ligamentous injuries $(0.2 \%)$ only identified with MRI. ${ }^{13-15}$ Most importantly, recent evidence demonstrates for obtunded trauma patients that even those with additional injuries found by advanced modalities such as MRI ultimately have no change in their management. ${ }^{16}$

With rapidly evolving guidelines, a degree of provider variation is expected. The magnitude of 
variation in the use of MRI for clearance of cervical collar in trauma patients is unknown. Therefore, it is important to better understand the current state of practice for cervical spine assessment in trauma patients to identify areas of quality improvement and identify factors that may necessitate further imaging in high-risk populations. In addition, MRI is an expensive modality that may lead to significantly increased cost, with no associated benefit. Campaigns such as Choosing Wisely are promoting the reduction of unnecessary waste in healthcare. ${ }^{17} 18$

The purpose of this study was to identify the extent of variation in the use of MRI in obtunded patients at risk of cervical spine injury. Secondary objectives included identifying relevant hospital-related and patient-related factors that could explain this variation. We hypothesized that there is a wide degree of variation in the use of MRI for collar clearance in obtunded, blunt trauma patients.

\section{METHODOLOGY}

\section{Study design and setting}

We performed a cross-sectional retrospective review of the National Trauma Data Bank (NTDB). We included data from 2007 to 2012, capturing a representative sample of 697 participating trauma receiving facilities. We followed a previously published 10-point checklist, which suggests approaches to large data set analyses. ${ }^{19}$ We also incorporated suggested best practice approaches to NTDB. ${ }^{2021}$

\section{Population}

There is no universally agreed on definition of an 'obtunded' trauma patient. The definition is loosely based on clinical examination and has been variably defined by many studies. There is no single data element in the NTDB, or any other large, administrative database to define 'obtunded'. Therefore, we defined obtunded adult patients at risk of blunt cervical spine injury using the following selection criteria: admission to a level 1 or 2 trauma center, age $\geq 18$ years, Glasgow Coma Scale $\leq 8$, Abbreviated Injury Scale-Head score of more than 3 and mechanically ventilated for $\geq 72$ hours. Patients with penetrating injuries, burns or minor injuries were excluded. All hospital types, rural and urban, teaching and non-teaching and at all geographic sites, were included.

\section{Variables and outcome measures}

The primary outcome measure was the use of MRI defined by an International Classification of Diseases, Ninth Revision (ICD-9) procedure code for spine MRI (ICD-9 88.93). Cervical spine injury was defined using ICD-9 diagnosis codes 805.00-805.18 (fracture of cervical vertebral column without mention of spinal cord injury), 806.00-806.19 (fracture of cervical vertebral column with spinal cord injury), 952.00-952.09 (cervical spinal cord injury without evidence of spinal bone injury), 839.00839.18 (dislocation of cervical vertebra), 847.0 (neck sprain), 848.2 (sprain of thyroid region), 925.2 (crushing injury of neck), 953.0 (injury to cervical nerve root) and 954.0 (injury to cervical sympathetic nerve).

Predictor variables included patient characteristics: age, gender, race, insurance status, injury severity, mechanism of injury and Injury Severity Score (ISS). We also included hospital characteristics: trauma center level designation, teaching status and regional geographic location.

\section{Statistical methods}

The prevalence of MRI use in the study population was identified. Patients having and not having an MRI were then compared by their patient-level and hospital-level characteristics. Differences were assessed using Pearson's $\chi^{2}$ test and Student's t-test as applicable. Risk-adjusted multivariable logistic regression models were constructed to identify predictors of MRI use by patient's characteristics. Our logistic regression models were further adjusted for clustering at the hospital level after accounting for patientlevel characteristics. Variables were selected in the model if they were significantly associated with MRI use in univariate analysis. The models were both adjusted for potential confounders (age, gender, race, insurance, ISS). Two-sided p-values $<0.05$ were considered statistically significant. All statistical analysis was performed using Stata V.13.

\section{RESULTS}

\section{Patient-level characteristics}

Of the 697 representative facilities captured in the NTDB, 395 were used in our study. A total of 32107 admissions to the 395 trauma centers met our inclusion criteria. Participants mean (SD) age was 43.3 (19.2) years. Of all the participants in the study population, $75.5 \%$ were males, $69.8 \%$ were white and $74 \%$ had medical insurance. Motor vehicle collision was the most common mechanism of injury (59.5\%) followed by falls (25.9\%). A total of $6641(20.1 \%)$ patient admissions had a cervical spine injury.

Three thousand one hundred and eighty-four (9.9\%) patients had a spine MRI. The table 1 shows characteristics of participants who received an MRI versus those who did not. A significantly higher proportion of MRIs were done for the age group 65-74 years $(15.7 \%, \mathrm{p}<0.01)$, non-Hispanic race $(6.3 \%, \mathrm{p}<0.01)$, patients with medical insurance $(12 \%$ vs $8.2 \%, \mathrm{p}<0.01)$, motor vehicle and pedestrian injuries $(11.3 \%$ and $11.9 \%, \mathrm{p}<0.01)$ and the most severe injuries with an ISS of $25-75(10 \%, \mathrm{p}<0.01)$. There was no significant gender difference in the use of MRI.

\section{Hospital-level characteristics}

Within the 395 included trauma centers, 29186 (90.9\%) admissions were at non-profit hospitals, 19167 (59.7\%) were at university hospitals and $23722(73.9 \%)$ were in state-verified level 1 centers.

There was a significant difference in the proportion of MRIs between non-profit versus for-profit hospitals (10.2\% vs 7.9\%, $\mathrm{p}<0.01$ ) (table 2). There was also a significant difference in proportions of MRIs between university hospitals versus non-teaching versus community hospitals $(8.7 \%$ vs $11.2 \%$ vs $11.8 \%, \mathrm{p}<0.01)$. There were also differences by hospital level, level 1 versus level 2 trauma centers $(10.5 \%$ vs $8.3 \%, \mathrm{p}<0.01)$ and the northeastern region versus other regions of the country $(21.8 \%$ vs $<10 \%$ each, $\mathrm{p}<0.01)$ (table 2$)$.

\section{Variation in use of MRI}

We calculated the proportion of patients who received MRIs per hospital. The figure 1 illustrates the variation of use of MRI among the 395 trauma centers. Two hundred and fourteen hospitals (42.1\% of all admissions) did not report an MRI on a single admission for an obtunded, blunt trauma patient. The remaining 181 hospitals (45.8\% of included hospitals) had at least one obtunded, blunt trauma patient receiving a spine MRI. These hospitals contained the majority of all NTDB obtunded, blunt trauma admissions (57.8\%) and demonstrated a wide variation of MRI use where the prevalence of MRI for the patient population ranged from $0.5 \%$ to $68.7 \%$. 


\begin{tabular}{|c|c|c|c|c|}
\hline & $\begin{array}{l}\text { Total } \\
\text { N (\%) }\end{array}$ & $\begin{array}{l}\text { MRI } \\
\text { N (\%) }\end{array}$ & $\begin{array}{l}\text { No MRI } \\
\text { N (\%) }\end{array}$ & $P$ value \\
\hline Total & $32107(100.00)$ & 3184 (9.92) & 28923 (90.08) & \\
\hline \multicolumn{5}{|l|}{ Age } \\
\hline $18-24$ & 7085 (22.07) & $763(10.77)$ & $6322(89.23)$ & \multirow[t]{8}{*}{$<0.01$} \\
\hline $25-34$ & $5846(18.21)$ & 640 (10.95) & $5206(89.05)$ & \\
\hline $35-44$ & 4637 (14.44) & $481(10.37)$ & 4156 (89.63) & \\
\hline $45-54$ & 5479 (17.06) & $532(8.78)$ & 4947 (90.29) & \\
\hline $55-64$ & $3917(12.20)$ & $386(13.58)$ & 3531 (90.15) & \\
\hline $65-74$ & $2459(7.66)$ & $196(15.70)$ & $2263(92.03)$ & \\
\hline $75-84$ & $2055(6.40)$ & $137(9.54)$ & 1918 (93.33) & \\
\hline $85+$ & $629(1.96)$ & 49 (7.79) & $580(92.21)$ & \\
\hline \multicolumn{5}{|l|}{ Gender } \\
\hline Females & 7735 (24.09) & 804 (10.39) & 6931 (89.61) & \multirow[t]{2}{*}{0.092} \\
\hline Males & $24227(75.46)$ & 2359 (9.74) & $21868(90.26)$ & \\
\hline \multicolumn{5}{|l|}{ Race } \\
\hline White & $22400(69.77)$ & $2386(10.65)$ & $20014(89.35)$ & \multirow[t]{4}{*}{$<0.01$} \\
\hline Black & $3360(10.47)$ & $308(9.17)$ & $3052(90.83)$ & \\
\hline Hispanic & 3720 (11.59) & $236(6.34)$ & 3484 (93.66) & \\
\hline Other & $1533(4.77)$ & $130(8.48)$ & 1403 (91.52) & \\
\hline \multicolumn{5}{|l|}{ Insurance } \\
\hline No & $4755(14.81)$ & $389(8.18)$ & $4366(91.82)$ & \multirow[t]{2}{*}{$<0.01$} \\
\hline Yes & $23549(73.35)$ & $2813(11.95)$ & 21125 (89.71) & \\
\hline \multicolumn{5}{|l|}{ Mechanism } \\
\hline MVA & $19105(59.50)$ & $2158(11.30)$ & 16947 (88.70) & \multirow[t]{5}{*}{$<0.01$} \\
\hline Pedestrian & $503(5031.57)$ & $60(11.93)$ & $443(88.07)$ & \\
\hline Fall & $8315(25.90)$ & $610(7.34)$ & 7705 (92.66) & \\
\hline Struck-by & $1831(5.70)$ & $135(7.37)$ & $1696(92.63)$ & \\
\hline Other & $2353(7.33)$ & 221 (9.39) & $2132(90.61)$ & \\
\hline \multicolumn{5}{|c|}{ Injury Severity Score } \\
\hline$<16$ & $1867(5.81)$ & $163(8.73)$ & $1704(91.27)$ & \multirow[t]{3}{*}{$<0.01$} \\
\hline $16-24$ & $6784(21.13)$ & $586(8.64)$ & 6198 (91.36) & \\
\hline $25-75$ & $23443(73.02)$ & $2436(10.39)$ & 21008 (89.61) & \\
\hline
\end{tabular}

Prediction model of MRI use based on a multilevel modeling of patient-level and hospital-level factors

Younger patients, with injuries from motor vehicle collisions and pedestrian injuries, were more likely to receive an MRI compared with their counterparts. When controlling for other factors, injury severity was not associated with the use of MRI. Community and non-teaching hospitals were twice as likely to perform MRIs compared with university hospitals. Level 1 centers and northeastern US hospitals were more likely to perform an MRI than others (table 3 ).

\section{DISCUSSION}

This study uses the NTDB trauma data set to assess variation in the use of MRI to rule out cervical spine injuries among obtunded, adult, blunt trauma patients. The results here are consistent with our hypothesis that a wide degree of variation exists that is not fully explained by patient-specific factors such as injury severity. We identified specific hospital characteristics associated with potential overutilization of spine MRI in obtunded patients. Non-academic and community hospitals
Table 2 Hospital-level characteristics

\begin{tabular}{|c|c|c|c|c|}
\hline $\begin{array}{l}\text { Total facilities } \\
(\mathrm{n}=395)\end{array}$ & $\begin{array}{l}\text { Total } \\
\text { admissions }\end{array}$ & $\begin{array}{l}\text { MRI } \\
\mathrm{N}(\%) \\
\end{array}$ & $\begin{array}{l}\text { No MRI } \\
\text { N (\%) }\end{array}$ & $P$ value \\
\hline Total & 32125 & 3185 (9.91) & $28940(90.09)$ & \\
\hline \multicolumn{5}{|l|}{ Hospital type } \\
\hline For profit $(n=39)$ & 2725 & $215(7.89)$ & $2510(92.11)$ & \multirow[t]{2}{*}{$<0.01$} \\
\hline Non-profit $(n=355)$ & 29186 & $2969(10.17)$ & $26217(89.83)$ & \\
\hline \multicolumn{5}{|l|}{ Teaching status } \\
\hline Community ( $n=173$ ) & 10273 & $1211(11.79)$ & $9062(88.21)$ & \multirow[t]{3}{*}{$<0.01$} \\
\hline Non-teaching $(\mathrm{n}=70)$ & 2667 & $298(11.17)$ & $2369(88.83)$ & \\
\hline University $(n=152)$ & 19167 & 1675 (8.74) & $17492(91.26)$ & \\
\hline Trauma center level & 2667 & $298(11.17)$ & $2369(88.83)$ & \\
\hline Level $1(n=178)$ & 23722 & 2489 (10.49) & $21233(89.51)$ & \multirow[t]{2}{*}{$<0.01$} \\
\hline Level $2(n=217)$ & 8385 & 695 (8.29) & 7690 (91.71) & \\
\hline \multicolumn{5}{|l|}{ Geographic region } \\
\hline Midwest ( $n=108$ ) & 6342 & $663(10.45)$ & $5679(89.55)$ & \multirow[t]{4}{*}{$<0.01$} \\
\hline Northeast $(n=80)$ & 5408 & $1182(21.86)$ & $4226(78.14)$ & \\
\hline South $(n=120)$ & 14501 & $1010(6.97)$ & 13491 (93.03) & \\
\hline West $(n=80)$ & 5662 & $325(5.74)$ & $5337(94.26)$ & \\
\hline
\end{tabular}

were more likely to perform MRIs compared with teaching institutions, and level 1 centers were more likely to perform MRIs than level 2 centers. We attribute these differences to a potential lack of standardized protocols in non-teaching trauma hospitals and lack of MRI access in lower level centers as has been previously suggested. ${ }^{22}$

Furthermore, we identified that hospitals in the northeastern region had the greatest utilization of MRIs in the obtunded, blunt trauma patient population compared with other regions. Geographic cost variation is a known consideration in cost analysis studies using data from the USA, and the northeastern regions (New England, Middle Atlantic) have the highest reported mean costs of stay and mean lengths of stay. ${ }^{23}$ These

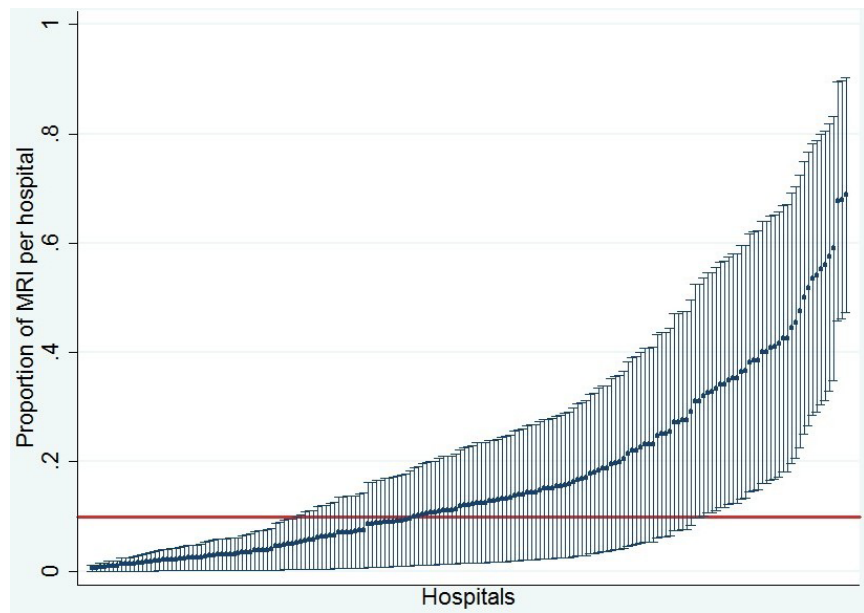

Figure 1 Variation of MRI use for cervical spine clearance in obtunded, blunt trauma patients across level 1 and 2 trauma centers in the National Trauma Data Bank (NTDB). The variation of use of MRI among 181 hospitals (45.8\% of included hospitals) had at least one obtunded, blunt trauma patient who receive a spine MRI. Each vertical bar represents the $95 \% \mathrm{Cl}$ around the proportion of included patients receiving MRI at each individual hospital. The red line shows the overall mean proportion of MRI for the entire cohort. 
Table 3 Patient-level and hospital-level predictors of MRI use in obtunded, adult trauma patients

\begin{tabular}{|c|c|c|}
\hline & OR $(95 \% \mathrm{Cl})$ & $P$ value \\
\hline \multicolumn{3}{|l|}{ Age } \\
\hline $18-24$ & (Ref) & \\
\hline $25-34$ & $1.12(0.982$ to 1.273$)$ & 0.092 \\
\hline $35-44$ & 1.03 (0.902 to 1.186$)$ & 0.625 \\
\hline $45-54$ & 1.00 (0.867 to 1.152$)$ & 0.992 \\
\hline $55-64$ & $1.00(0.849$ to 1.171$)$ & 0.969 \\
\hline $65-74$ & 0.83 (0.685 to 0.994$)$ & 0.043 \\
\hline $75-84$ & 0.62 (0.483 to 0.792$)$ & $<0.01$ \\
\hline $85+$ & 0.76 (0.545 to 1.055$)$ & 0.101 \\
\hline \multicolumn{3}{|l|}{ Sex } \\
\hline Female & (Ref) & 0.060 \\
\hline Male & 0.91 (0.826 to 1.004$)$ & \\
\hline \multicolumn{3}{|l|}{ Race } \\
\hline White & (Ref) & \\
\hline Black & 1.00 (0.811 to 1.236$)$ & 0.988 \\
\hline Hispanic & $0.79(0.590$ to 1.044$)$ & 0.096 \\
\hline Other & $0.87(0.645$ to 1.174$)$ & 0.362 \\
\hline \multicolumn{3}{|l|}{ Insurance } \\
\hline No & (Ref) & 0.942 \\
\hline Yes & 1.01 (0.778 to 1.310$)$ & \\
\hline \multicolumn{3}{|l|}{ Injury Severity Score } \\
\hline $25-27$ & (Ref) & \\
\hline $16-24$ & 0.96 (0.692 to 1.321$)$ & 0.785 \\
\hline$<16$ & 0.93 (0.782 to 1.107$)$ & 0.415 \\
\hline \multicolumn{3}{|l|}{ Mechanism } \\
\hline Motor vehicle crash & (Ref) & \\
\hline Fall & $0.57(0.494$ to 0.658$)$ & $<0.01$ \\
\hline Pedestrian & 0.93 (0.702 to 1.226$)$ & 0.599 \\
\hline Struck-by & 0.64 (0.526 to 0.785$)$ & $<0.01$ \\
\hline Other & 0.85 (0.691 to 1.046$)$ & 0.126 \\
\hline \multicolumn{3}{|l|}{ Type of hospital } \\
\hline For profit & (Ref) & \\
\hline Non-profit & 1.15 (0.464 to 2.834$)$ & 0.767 \\
\hline \multicolumn{3}{|l|}{ Teaching status } \\
\hline University & (Ref) & \\
\hline Community & 2.08 (1.192 to 3.637$)$ & 0.010 \\
\hline Non-teaching & 2.75 (1.233 to 6.133$)$ & 0.013 \\
\hline \multicolumn{3}{|l|}{ Trauma center level } \\
\hline Level 1 & (Ref) & \\
\hline Level 2 & $0.47(0.281$ to 0.801$)$ & 0.005 \\
\hline \multicolumn{3}{|l|}{ Geographic region } \\
\hline Northeast & (Ref) & \\
\hline Midwest & 0.29 (0.16 to 0.51$)$ & $<0.01$ \\
\hline South & 0.22 (0.12 to 0.38$)$ & $<0.01$ \\
\hline West & $0.16(0.08$ to 0.31$)$ & $<0.01$ \\
\hline
\end{tabular}

findings have been reproduced in similar nationwide analyses of surgical patients, and explanations remain inconclusive but include cost of living differences, degree of regulatory control and differences in admission diagnoses. ${ }^{24-26}$ In emergency and trauma surgery, regional variation also persists but tends to be less consistent with different regions leading costs for different admission diagnoses. ${ }^{27}$

Although the mean MRI use in this population is 9.9\%, some trauma centers make up the disproportionate number of MRIs used for cervical spine clearance. The fact that $>45 \%$ of trauma centers are using MRI at all, which is higher than previously reported survey data and literature, demonstrates inconsistency with current national recommendations. ${ }^{22} \mathrm{~A}$ recent prospective WTA multi-institutional trial demonstrated that CT scan was highly accurate and reliable for clearing cervical spine in the intoxicated patient population. CT had a $99.5 \%$ specificity and a $99.5 \%$ negative predictive value for identifying cervical spine injuries. ${ }^{28}$

A prospective study of 197 patients performed by Como et al relied on negative CT scans to clear collars in the obtunded, blunt trauma patients with gross movement of all four extremities; only one injury was diagnosed by MRI after negative CT scan of the cervical spine. It was that supplemental MRI was not necessary in this patient population and was subsequently removed from their algorithm. ${ }^{29}$

These findings played a role in shaping the EAST practice guideline, which recommend removal of cervical collars in the obtunded, adult blunt trauma patient after negative highquality CT. This is primarily due to the negative predictive value of $91 \%$ with high-quality CT imaging. ${ }^{14}$

The variability in MRI utilization for cervical spine clearance in obtunded trauma patients is not adequately explained by patient-level factors and suggests that the changes in published peer-reviewed literature are yet to be adapted within hospital protocols. This may support prior concerns that decisions are being left to individual providers. ${ }^{22}$ Numerous groups recommend in the obtunded, blunt adult patient population that negative high-quality CT scans are sufficient to clear cervical collars, and MRI should be limited to cases when CT scan is non-informative or difficult to interpret.

The Choosing Wisely campaign has already noted a number of clinical scenarios where high-cost, low-utility imaging is currently being overused. ${ }^{30-32}$ We would further emphasize that the acuity of a trauma patient does not necessarily exempt them from the same health resource utilization concerns. Given the evidence and guideline support for decreased use of MRI, trauma providers have an obligation to consider the limited benefit of MRI for cervical spine clearance versus the widely available and lower cost CT alternative.

Finally, the prolonged immobilization exposes patients to a multitude of collar-related risks. Pressure ulcers increase exponentially every additional day the collar remains in place. Life-saving procedures such as intubation, tracheostomy and central line insertion become more challenging to perform by the provider. Lastly, the simple task of transporting a patient to MRI is not without risks: increased ICP when laying flat, accidental extubation or risk of aspiration. The overall riskbenefit ratio of prolonged cervical collar in addition to MRI versus cervical spine clearance must be closely assessed by the providers. $^{3-7}$

\section{Limitations}

Akin to limitations of all administrative data sets, ${ }^{33}$ this study was limited by possible under-reporting of codes in the NTDB that may have resulted in underestimation of the proportion of MRIs in our study. Some low-cost imaging is thought to be missing from administrative, billing data sets, ${ }^{33}$ although it is unknown if this exists for data sets such as the NTDB, whose 
primary purpose is clinical care. Further, the NTDB uses ICD-9 procedure codes and not Current Procedures Terminology codes which are more specific. We are also limited by our ability to identify the reason patients undergo an MRI. Perhaps some are clinically indicated and justified to receive an MRI after an inadequate CT, to further evaluate fractures identified on CT scan, or based on clinical symptoms. Despite these limitations, we provide evidence suggesting widely varying provider and hospital practices and demonstrate these findings using the largest available data drawn from trauma admissions across the USA.

\section{CONCLUSION}

We observed a wide variability in the utilization of MRIs for cervical spine clearance in the obtunded, blunt trauma patients (0\%-68\%). Patient-level characteristics did not sufficiently explain this wide variability. This may be due to physicians not being up to date with best practice care, unavailability of locally adopted protocols in institutions or lack of consensus among clinical providers. Moving forward, we promote clearing collars after negative high-quality CT scan of the cervical spine in the obtunded, blunt trauma adult patient population to improve patient outcomes and simultaneously minimizing cost of unnecessary MRI.

Twitter@IraLeeds_MD@candeux @JosephSakran@elliotthaut

Funding The authors have not declared a specific grant for this research from any funding agency in the public, commercial or not-for-profit sectors.

Competing interests ERH is supported by a grant from the AHRQ (1R01HS024547) entitled 'Individualized Performance Feedback on Venous Thromboembolism Prevention Practice', a contract (CE-12-11-4489) from the Patient Centered Outcomes Research Institute (PCORI) entitled 'Preventing Venous Thromboembolism: Empowering Patients and Enabling Patient-Centered Care via Health Information Technology', a contract from PCORI entitled 'Preventing Venous Thromboembolism (VTE): Engaging Patients to Reduce Preventable Harm from Missed/Refused Doses of VTE Prophylaxis' and a grant from the NIH/NHLBI (R21HL129028) entitled 'Analysis of the Impact of Missed Doses of Venous Thromboembolism Prophylaxis'. ERH is a paid consultant and speaker for the 'Preventing Avoidable Venous Thromboembolism—Every Patient, Every Time' VHA/ Vizient IMPERATIV® Advantage Performance Improvement Collaborative. ERH receives royalties from Lippincott, Williams, Wilkins for a book-'Avoiding Common ICU Errors'. Dr Haut was the paid author of a paper commissioned by the National Academies of Medicine titled 'Military Trauma Care's Learning Health System: The Importance of Data Driven Decision Making' which was used to support the report titled 'A National Trauma Care System: Integrating Military and Civilian Trauma Systems to Achieve Zero Preventable Deaths After Injury'.

Patient consent for publication Not required.

Ethics approval Institutional review board approval was obtained from Johns Hopkins Medicine Institutional Review Board.

Provenance and peer review Not commissioned; externally peer reviewed.

Data availability statement Data may be obtained from a third party and are not publicly available.

Open access This is an open access article distributed in accordance with the Creative Commons Attribution Non Commercial (CC BY-NC 4.0) license, which permits others to distribute, remix, adapt, build upon this work non-commercially, and license their derivative works on different terms, provided the original work is properly cited, appropriate credit is given, any changes made indicated, and the use is non-commercial. See: http://creativecommons.org/licenses/by-nc/4.0/.

\section{REFERENCES}

1. Obirieze AC, Gaskin DJ, Villegas CV. Lifetime direct costs after spinal cord injury. Top Spinal Cord Inj Rehabil 2011:16:10-16.

2. Milby AH, Halpern $\mathrm{CH}$, Guo W, Stein SC. Prevalence of cervical spinal injury in trauma. Neurosurg Focus 2008:25:E10.

3. Ackland HM, Cooper JD, Malham GM, Kossmann T. Factors predicting cervical collarrelated decubitus ulceration in major trauma patients. Spine 2007;32:423-8.

4. Dunham CM, Brocker BP, Collier BD, Gemmel DJ. Risks associated with magnetic resonance imaging and cervical collar in comatose, blunt trauma patients with negative comprehensive cervical spine computed tomography and no apparent spinal deficit. Crit Care 2008;12:R89.

5. Pennant JH, Pace NA, Gajraj NM. Role of the laryngeal mask airway in the immobile cervical spine. J Clin Anesth 1993:5:226-30.

6. Raphael JH, Chotai R. Effects of the cervical collar on cerebrospinal fluid pressure. Anaesthesia 1994:49:437-9.

7. Andrews PJD, Piper IR, Dearden NM, Miller JD. Secondary insults during intrahospital transport of head-injured patients. The Lancet 1990:335:327-30

8. Morris CGT, McCoy É.. Clearing the cervical spine in unconscious polytrauma victims, balancing risks and effective screening. Anaesthesia 2004;59:464-82

9. Velopulos CG, Shihab HM, Lottenberg L, Feinman M, Raja A, Salomone J, Haut ER Prehospital spine immobilization/spinal motion restriction in penetrating trauma: A practice management guideline from the Eastern Association for the Surgery of Trauma (EAST). J Trauma 2018;84:736-44

10. Haut ER, Kalish BT, Efron DT, Haider AH, Stevens KA, Kieninger AN, Cornwell EE, Chang DC. Spine immobilization in penetrating trauma: more harm than good? J Trauma 2010:68:115-21.

11. Brown JB, Bankey PE, Sangosanya AT, Cheng JD, Stassen NA, Gestring ML. Prehospita spinal immobilization does not appear to be beneficial and may complicate care following gunshot injury to the torso. J Trauma 2009;67:774-8.

12. Thiboutot F, Nicole PC, Trépanier CA, Turgeon AF, Lessard MR. Effect of manual in-line stabilization of the cervical spine in adults on the rate of difficult orotracheal intubation by direct laryngoscopy: a randomized controlled trial. Can J Anesth/J Can Anesth 2009:56:412-8.

13. Como JJ, Diaz JJ, Dunham CM, Chiu WC, Duane TM, Capella JM, Holevar MR, Khwaja KA, Mayglothling JA, Shapiro MB, et al. Practice management guidelines for identification of cervical spine injuries following trauma: update from the eastern association for the surgery of trauma practice management guidelines committee. $J$ Trauma 2009:67:651-9.

14. Patel MB, Humble SS, Cullinane DC, Day MA, Jawa RS, Devin CJ, Delozier MS, Smith LM, Smith MA, Capella JM, et al. Cervical spine collar clearance in the obtunded adult blunt trauma patient. J Trauma Acute Care Surg 2015;78:430-41.

15. Sliker CW, Mirvis SE, Shanmuganathan K. Assessing cervical spine stability in obtunded blunt trauma patients: review of medical literature. Radiology 2005:234:733-9.

16. Como JJ, Thompson MA, Anderson JS, Shah RR, Claridge JA, Yowler CJ, Malangoni MA. Is magnetic resonance imaging essential in clearing the cervical spine in obtunded patients with blunt trauma? J Trauma 2007;63:544-9.

17. Casarett $D$. The dcience of Choosing Wisely - overcoming the therapeutic illusion. $N$ Engl J Med 2016;374:1203-5

18. Morden NE, Colla CH, Sequist TD, Rosenthal MB. Choosing wisely - the politics and economics of labeling low-value services. N Engl J Med 2014;370:589-92.

19. Hashmi ZG, Kaji AH, Nathens AB. Practical guide to surgical data sets: National Trauma Data Bank (NTDB). JAMA Surg 2018:153:852.

20. Haider AH, Bilimoria KY, Kibbe MR. A checklist to elevate the science of surgical database research. JAMA Surg 2018:153:505.

21. Haider AH, Hashmi ZG, Zafar SN, Castillo R, Haut ER, Schneider EB. Developing best practices to study trauma outcomes in large databases; an evidencebased approach to determine the best mortality risk adjustment tool. J Trauma 2014;76:1061-9.

22. Theologis AA, Dionisio R, Mackersie R, McClellan RT, Pekmezci M. Cervical spine clearance protocols in level 1 trauma centers in the United States. Spine 2014:39:356-61.

23. Congressional Budget Office. Geographic Variation in Health Care Spending. Washington, DC. 2008. https://www.cbo.gov/sites/default/files/cbofiles/ftpdocs/89xx/ doc8972/02-15-geoghealth.pdf (22 Jul 2016).

24. Cerullo M, Chen SY, Dillhoff M, Schmidt C, Canner JK, Pawlik TM. Association of hospital market concentration with costs of complex Hepatopancreaticobiliary surgery. JAMA Surg 2017:152:e172158.

25. Makarov DV, Loeb S, Landman AB, Nielsen ME, Gross CP, Leslie DL, Penson DF, Desai RA. Regional variation in total cost per radical prostatectomy in the healthcare cost and utilization project nationwide inpatient sample database. J Urol 2010;183:1504-9.

26. Reinke CE, Sonnenberg EM, Karakousis GC, Fraker DL, Kelz RR. Variation in cost of total thyroidectomy across the United States, 2007 to 2008. Am J Surg 2015;210:302-8

27. Obirieze AC, Gaskin DJ, Villegas CV, Bowman SM, Schneider EB, Oyetunji TA, Haut ER, Efron DT, Cornwell EE, Haider AH. Regional variations in cost of trauma care in the United States. J Trauma Acute Care Surg 2012;73:516-22.

28. Martin MJ, Bush LD, Inaba K, Byerly S, Schreiber M, Peck KA, Barmparas G, Menaker J, Hazelton JP, Coimbra R, et al. Cervical spine evaluation and clearance in the intoxicated patient: A prospective Western Trauma Association Multi-Institutional Trial and Survey. J Trauma Acute Care Surg 2017;83:1032.

29. Como JJ, Leukhardt WH, Anderson JS, Wilczewski PA, Samia H, Claridge JA. Computed tomography alone may clear the cervical spine in obtunded blunt trauma patients: a prospective evaluation of a revised protocol. J Trauma 2011;70:345-51. 
30. American Podiatric Medical Association. Don't routinely use MRI to diagnose bone infection (osteomyelitis) in the foot. In Choosing Wisely. 2017. http://www. choosingwisely.org/clinician-lists/apma-mri-to-diagnose-osteomyelitis-in-the-foot/ (Accessed 6 Jun 2018)

31. American Association for the Study of Liver Diseases. Don't perform computed tomography or magnetic resonance imaging routinely to monitor benign focal lesions in the liver unless there is a major change in clinical findings or symptoms. In Choosing Wisely. 2014. http://www.choosingwisely.org/clinician-lists/americanassociation-study-liver-disease-ct-or-mri-to-monitor-benign-focal-lesions/ (Accessed 6 Jun 2018)
32. American Medical Society for Sports Medicine. Avoid ordering a brain CT or brain MRI to evaluate an acute concussion unless there are progressive neurological symptoms, focal neurological findings on exam or there is concern for a skull fracture. In Choosing Wisely. 2014. http://www.choosingwisely.org/clinician-lists/americanmedical-society-sports-medicine-brain-ct-or-mri-to-evaluate-acute-concussion/ (Accessed 6 Jun 2018).

33. Haut ER, Pronovost PJ, Schneider EB. Limitations of administrative databases. JAMA 2012:307:2589-90. 